\title{
Free Testosterone and Weakly Bound to Total Testosterone Ratio Measurement
}

National Cancer Institute

\section{Source}

National Cancer Institute. Free Testosterone and Weakly Bound to Total Testosterone

Ratio Measurement. NCI Thesaurus. Code C147440.

The determination of the ratio of free and weakly bound testosterone compared to total testosterone present in a sample. The measurement may be expressed as a ratio or percentage. 